Rev. Bras. Saúde Prod. Anim., Salvador, v.17, n.3, p.461-473 jul./set., $2016 \quad \underline{\text { http://www.rbspa.ufba.br }}$

\title{
Avaliação bioeconômica de estratégias de suplementação de novilhos zebuínos mantidos em pastagens diferidas de capim-marandu no período seco $^{1}$
}

\author{
Bioeconomic evaluation of supplementation strategies of zebuine steers grazing on \\ stockpilled palisade grass in the dry season
}

QUADROS, Danilo Gusmão de ${ }^{2 *}$; SOUZA, Heraldo Namorato de ${ }^{3}$; ANDRADE, Alexandro Pereira ${ }^{2}$; BEZERRA, André Ricardo Gomes ${ }^{4}$; ALMEIDA, Raimundo Guedes $\mathrm{de}^{2}$; SÁ, Alberto Magalhães de ${ }^{2}$; OLIVEIRA, Daiana Nara de ${ }^{5}$; FRANCO, Gumercindo Loriano ${ }^{6}$

\footnotetext{
${ }^{1}$ Financiado pela PETROBRAS.

${ }^{2}$ Universidade do Estado da Bahia, Faculdade de Agronomia, Núcleo de Estudo e Pesquisa em Produção Animal, Barreiras, Bahia, Brasil.

${ }^{3}$ PETROBRAS, CENPES, PDEDS, GEGQ, Rio de Janeiro, Brasil.

${ }^{4}$ Universidade Federal de Viçosa, Departamento de Fitotecnia, Viçosa, Minas Gerais, Brasil.

${ }^{5}$ EMBRAPA, Brasília, Distrito Federal, Brasil.

${ }^{6}$ Universidade Federal de Mato Grosso do Sul, Faculdade de Medicina Veterinária e Zootecnia, Campo Grande, Mato Grosso do Sul, Brasil.

*Endereço para correspondência: daniloquadros@hotmail.com
}

\section{RESUMO}

O objetivo com este trabalho foi avaliar estratégias de suplementação sobre o consumo de suplemento, comportamento e desempenho de novilhos zebuínos mantidos em pastagem de capim-marandu (Urochloa brizantha cv. Marandu) diferido. Foi utilizado delineamento inteiramente casualizado para testar cinco estratégias de suplementação: sal mineral (SM), sal proteinado com $25 \%$ de ureia (SP) e três multimisturas (45,5\% NDT) com 10\% (MM10), $15 \%$ (MM 15), ou 20\% (MM20) de ureia. Foram utilizados vinte novilhos com peso inicial $300 \pm 24,9 \mathrm{~kg}$, sendo quatro por tratamento, mantidos em cinco piquetes de 3 , 4 ha rotacionados semanalmente, de julho a outubro de 2010. Os dados foram submetidos à ANOVA, usando o Teste de Tukey para comparar as médias $(\mathrm{P}<0,05)$; entretanto, a análise econômica determinou a melhor estratégia. A ingestão de suplementos foi alterada $\quad(\mathrm{P}<0,05)$ pela estratégia de suplementação, sendo de: 106, 196, 852, 666 e 400 g/animal/dia para SM, SP, MM10, MM15 e MM20, respectivamente. O aumento do consumo de suplementos não alterou o tempo de pastejo ou ruminação/ócio $(\mathrm{P}>0,05)$. SM resultou em perda de peso (-137 g/animal/dia). Utilizando-se o SP praticamente manteve o peso dos novilhos. Entretanto, para obtenção de ganho de peso, as multimisturas devem ser utilizadas $(\mathrm{P}<0,05)$. Nesses casos, o ganho de peso diário chegou a 324 g/animal (MM10). Baseado nos resultados econômicos, a melhor estratégia foi MM20, seguida de MM10.

Palavras-chave: comportamento, consumo, desempenho, suplemento, ureia

\section{SUMMARY}

The objective of this work was to evaluate different supplementation strategies on supplement intake, behavior, and performance of beef steers grazing stockpiled palisade grass (Urochloa brizantha cv. Marandu) pastures. There was used a completely randomized design trial to test five supplementation strategies: commercial mineral (SM), mineral plus $25 \%$ of urea (SP), and three multimixtures $(45.5 \% \mathrm{TDN})$ with $10 \%$ (MM10), $15 \%$ (MM 15), or $20 \%$ (MM20) of urea. Twenty zebuine steers weighting $300 \pm 24.9 \mathrm{~kg}$ of initial body weight, being four animals per treatment, were raised on five paddocks of 3.4 hectares under weekly rotation, from July to October of 2010. 
Data were submitted to ANOVA, using Tukey's test to compare average values $(\mathrm{P} \leq 0.05)$; however, economic analysis determined the best strategy. Supplementation did not affect the grazing or rumination/resting time $(\mathrm{P}>0.05)$. The intake of supplements was affected $(\mathrm{P}<0.05)$ by supplementation strategy, being 106, 196, 852, 666, and $400 \mathrm{~g}$ /day for SM, SP, MM10, MM15, and MM20, respectively. SM resulted in losing weight (-137 g/animal/day). Using SP practically maintained the cattle weight. However, if gains are desired, multimixtures should be used $(\mathrm{P}<0.05)$. In those cases, daily weight gain reached 324 g/animal (MM10). Based on economic analysis, the best strategy was MM20, followed by MM10.

Keywords: behavior, intake, performance, supplement, urea

\section{INTRODUÇÃO}

A limitação quantitativa e qualitativa de forragem que ocorre na época seca do ano afeta a produção animal de maneira significativa (ZANETTI et al., 2000; REIS et al., 2012). Em tal condição, os bovinos são submetidos a carências nutricionais múltiplas e a proteína (compostos nitrogenados) assume papel prioritário, uma vez que o alimento disponível ou a reciclagem endógena de nitrogênio não atende aos requerimentos microbianos, incorrendo em limitação no crescimento e na atividade dos mesmos, bem como queda na digestibilidade da parede celular, o que acarreta em diminuição do consumo de forragem e do desempenho animal (HERSOM, 2008; CAPPELLOZZA et al., 2013).

A suplementação de bovinos em pastagem tem como objetivos cobrir deficiências dietéticas das forragens e permitir ao animal aumentar o consumo de nutrientes digestíveis, aumentando o desempenho, aumentar o retorno econômico e manejar o comportamento do gado (KUNKLE et al., 2000; SILVA et al., 2010; MATEUS et al., 2011; CANESIN et al., 2014).

Nesse contexto, a suplementação com fontes de proteína de alta degradabilidade ruminal, ou nitrogênio não proteico como a uréia, para animais em pastejo promove aumento na síntese microbiana e na taxa de passagem, resultando na elevação do consumo de forragem (MOORE et al., 1999; McGUIRE et al., 2013). Essa prática tem propiciado melhorias no desempenho animal em condições tropicais (CABRAL et al., 2014; DETMANN et al., 2014).

O objetivo deste trabalho foi avaliar diferentes estratégias de suplementação (sal mineral, sal proteinado e multimisturas) sobre o consumo de suplemento, comportamento e desempenho de novilhos zebuínos na fase de recria, mantidos em pastagens de capim-marandu durante a época seca do ano, sendo a análise econômica utilizada para determinar a melhor estratégia.

\section{MATERIAL E MÉTODOS}

O experimento foi conduzido na Fazenda Castelo II, localizada no Município de Barreiras - BA (12 ${ }^{\circ}$ 09' 10" S; 44 59' 24" W; 452m de altitude), de abril a outubro de 2010. O município encontra-se no bioma Cerrado, o qual é marcado por duas épocas bem definidas: chuvosa e seca, sendo esta última de março/abril a outubro/novembro.

A área de 17 ha de pastagem para a realização do experimento foi formada com o Urochloa brizantha (Stapf) Webster cv. Marandu (capim-marandu) em 2007. Antes de iniciar o experimento, o pasto foi diferido por um período de 75 dias.

A área foi subdividida em cinco piquetes de 3,4 ha e cochos constituídos 
de tambores plásticos de 200L cortados ao meio, com borda superior a $80 \mathrm{~cm}$ do nível do solo foram colocados, sendo $2 \mathrm{~m}$ lineares por piquete. Os animais tiveram acesso a água de boa qualidade ad libitum.

Foram utilizados 20 novilhos azebuados, predominantemente Nelore de aproximadamente $18 \pm 2$ meses de idade. Inicialmente, os animais foram pesados (jejum de 16 horas), identificados com brincos e dosificados com antihelmíntico. Logo em seguida, foram divididos em cinco grupos homogêneos de quatro animais, com peso corporal médio inicial de $300 \pm 24,9 \mathrm{~kg}$.

Os animais foram colocados nos piquetes onde permaneceram até o outubro, totalizando 105 dias, sendo 15 dias de adaptação mais 90 dias de período experimental. A cada sete dias os animais foram mudados de piquete, para eliminar o efeito do pasto, conforme a recomendação de Silva et al. (2008). A pesagem dos bovinos ocorreu a cada 28 dias, utilizando-se balança mecânica em um curral situado cerca de $300 \mathrm{~m}$ da área experimental, sem jejum, exceto na última pesagem, que seguiu o protocolo semelhante à primeira. Durante todo o período experimental não houve precipitação pluviométrica.
As estratégias de suplementação testadas foram: sal mineral comercial (SM), sal proteinado (SP) composto de sal mineral $+25 \%$ de ureia (Reforce $\mathrm{N}^{\circledR}$ PETROBRAS) e três misturas múltiplas (45,5\% NDT) compostas de milho, farelo de soja, sal comum, sal mineral, sulfato de amônio e 10\% (MM10), 15\% (MM $15)$ e $20 \%$ (MM20) de ureia, contendo 0 , $70,41,51$ e $63 \%$ de proteína bruta (PB), respectivamente (Tabela 1 ).

$\mathrm{O}$ sal mineral utilizado foi mistura comercial para recria de bovinos de corte, contendo os seguintes níveis de garantia em $\mathrm{g} / \mathrm{kg}$ (macroelementos) e $\mathrm{mg} / \mathrm{kg}$ (microelementos): Ca, $180 \mathrm{~g}$; $\mathrm{P}, 60 \mathrm{~g}$; Na, 107 g; S, 12 g; Mn, 5.000; Co, 107; Cu, 1.300 ; I, 70; Mn, 1.000; Se, 18; Zn, 4.000; Fe, 1.400; e F, máximo de 600).

Com base na composição do suplemento e no custo dos ingredientes (cada $\mathrm{kg}$ de milho, farelo de soja, sal comum, mistura mineral, Reforce $\mathrm{N}^{\circledR}$ e sulfato de amônio custou R\$ 0,$42 ; 0,90 ; 0,36 ; 1,63 ; 1,24 \mathrm{e}$ 0,75 , respectivamente) foi calculado o custo dos suplementos. Cada $\mathrm{kg}$ de suplemento custou R $\$ 1,63 ; 1,53 ; 0,77$; 0,77 e 0,79 ; respectivamente para as estratégias SM, SP, MM10, MM15 e MM20.

Tabela 1. Composição dos suplementos de acordo a estratégia de suplementação

\begin{tabular}{|c|c|c|c|c|c|}
\hline \multirow{3}{*}{ Ingredientes } & \multicolumn{5}{|c|}{ Estratégia de suplementação } \\
\hline & \multirow{2}{*}{$\begin{array}{l}\text { Sal mineral } \\
\quad(\mathrm{SM})\end{array}$} & \multirow[b]{2}{*}{$\begin{array}{l}\text { Sal proteinado } \\
\text { (SP) }\end{array}$} & \multicolumn{3}{|c|}{ Multimisturas } \\
\hline & & & $\begin{array}{c}10 \% \text { ureia } \\
\text { (MM10) }\end{array}$ & $\begin{array}{c}15 \% \text { ureia } \\
\text { (MM15) }\end{array}$ & $\begin{array}{c}20 \% \text { ureia } \\
\text { (MM20) }\end{array}$ \\
\hline $\begin{array}{l}\text { Suplemento } \\
\text { mineral }\end{array}$ & 100 & 75 & 15 & 15 & 15 \\
\hline Ureia & - & 25 & 10 & 15 & 20 \\
\hline $\begin{array}{l}\text { Sulfato } \\
\text { amônio }\end{array}$ & & - & 1,0 & 1,0 & 1,0 \\
\hline Farelo de soja & - & - & 19 & 10 & 5 \\
\hline Fubá de milho & - & - & 35 & 43 & 48 \\
\hline Sal comum & - & - & 20 & 16 & 11 \\
\hline PB (\%) & - & 70 & 40,8 & 51,0 & 63,0 \\
\hline NDT (\%) & - & - & 46,0 & 45,0 & 46,2 \\
\hline
\end{tabular}


O suplemento foi fornecido ad libitum e o consumo diário médio por animal foi quantificado semanalmente com base nos dados de pesagem da quantidade colocada e das sobras.

Mensalmente a altura das plantas foi determinada pela média de 30 medições por piquete, utilizando-se de uma régua graduada em centímetros. Notou-se diminuição na altura das plantas ao longo do período experimental de $1,4 \mathrm{~m}$ no início de julho para 1,$08 ; 0,95$ e $0,80 \mathrm{~m}$; em agosto, setembro e outubro, respectivamente.

$\mathrm{Na}$ mesma frequência foi medida a disponibilidade de forragem por meio do corte, a $5 \mathrm{~cm}$ de altura em relação ao nível do solo, e coleta do capim em cinco áreas delimitadas por um quadrado metálico de $0,5 \mathrm{~m} \times 0,5 \mathrm{~m}$, retiradas aleatoriamente em cada piquete. Após a pesagem da quantidade de forragem contida no interior do quadrado em campo, uma amostra de aproximadamente $500 \mathrm{~g}$ foi encaminhada ao Laboratório de Nutrição Animal e Pastagens do Campus IX da UNEB, em Barreiras, onde foi separada em folhas verdes (quando presentes), folhas secas e colmos, sendo cada fração submetida à secagem para determinação do percentual de matéria seca parcial (AOAC, 2000).

Com esses dados, foram calculadas a disponibilidade total de forragem e de cada componente morfológico (folha, colmo, folhas secas).

No Laboratório, após moagem em moinho tipo Willey, as amostras foram submetidas às análises de $\mathrm{PB}$, fibra em detergente neutro (FDN) e ácido (FDA), conforme Silva \& Queiroz (2002).

A coleta de dados das atividades comportamentais foi realizada com intervalo de 14 dias, com a observação realizada de uma torre $2 \mathrm{~m}$ de altura na parte central dos piquetes, parcialmente sob a copa de uma árvore, visando não interferir no comportamento normal dos animais. As observações foram realizadas durante $24 \mathrm{~h}$, por seis pessoas de forma escalonada, divididos em dois trios que se alternavam a cada período de doze horas. $\mathrm{Na}$ observação noturna dos animais foi utilizada luz artificial localizada (holofote), sendo que anteriormente ao experimento foram acesos flashes de luz para acostumar os animais. O registro das atividades se fez através de observação direta com coleta contínua, amostragem focal com auxílio de binóculo de longo alcance e intervalo amostral a cada dez minutos para os registros das atividades de pastejo, ruminação/ócio, cocho e outros comportamentos (MEZZALIRA et al., 2011).

Como tempo de pastejo foi considerado o período no qual ocorreu a prática de apreensão da forragem pelo animal, incluindo pequenos deslocamentos. Os tempos de ruminação e ócio foram combinados, considerando-se que não foi possível separar os dois tipos de comportamento devido à distância dos observadores e o ângulo do posicionamento dos animais, semelhante ao que foi realizado por Kilgour et al. (2012). O tempo de permanência no cocho foi considerado o tempo despendido no consumo de suplemento pelo animal e a sua permanência próxima ao cocho. Os outros comportamentos foram deslocamento e ingestão de água.

$\mathrm{O}$ delineamento experimental adotado foi inteiramente casualizado, com cinco tratamentos e quatro repetições. Os dados foram submetidos à ANOVA e as médias comparadas pelo Teste de Tukey $(\mathrm{P}<0,05)$, utilizando-se o Programa ASSISTAT.

Para se definir a melhor estratégia de suplementação, foi realizada a análise econômica, com base nos valores do suplemento e do preço pago ao produtor pela arroba do boi. 
Rev. Bras. Saúde Prod. Anim., Salvador, v.17, n.3, p.461-473 jul./set., $2016 \quad \underline{\text { http://www.rbspa.ufba.br }}$

\section{RESULTADOS E DISCUSSÃO}

Os resultados da disponibilidade e da qualidade da forragem em cada piquete foram compilados de forma mais simplificada, haja vista a eliminação do efeito da interação entre a estratégia de suplementação e a massa de forragem em decorrência da rotação do gado a cada sete dias. Como neste experimento não foi adotado o sistema "put-andtake" que permitiria o ajuste da oferta de forragem em cada tratamento, utilizou-se a troca dos animais de piquete, conforme sugerido por Silva et al. (2008).

A disponibilidade de forragem total inicial foi aproximadamente $7.000 \mathrm{~kg} / \mathrm{ha}$ decrescendo a cada ciclo de coleta até atingir $3.400 \mathrm{~kg} / \mathrm{ha}$ (Figura 1 ).

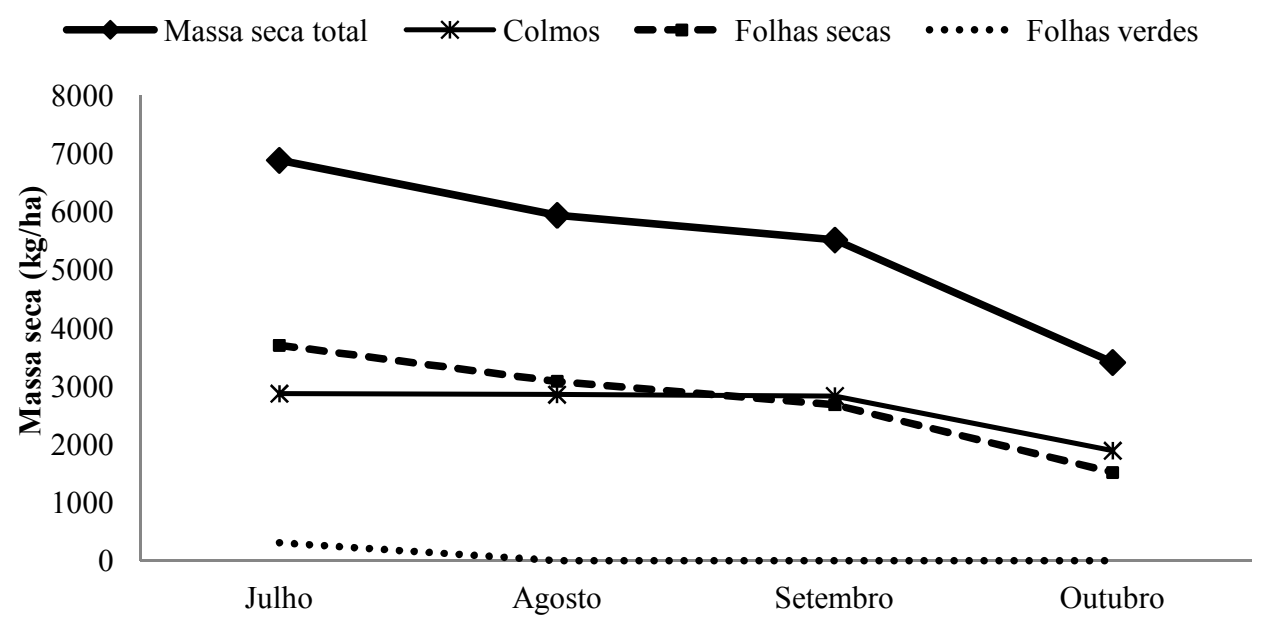

Figura 1.Massa de forragem durante o período experimental

As poucas folhas verdes remanescentes foram rapidamente consumidas pelos animais. Em seguida, foram as folhas secas, que de início superavam a massa de colmos, mas foram gradativamente diminuindo. A quantidade de colmos se manteve praticamente inalterada durante grande parte do período experimental, sendo reduzida apenas no final da seca (Figura 1).

Os resultados das análises bromatológicas indicaram uma forragem de baixo valor nutritivo com altos teores de fibra e baixos teores de proteína. As folhas verdes, seca e colmos apresentaram concentração de FDN: 64 ; 74 e 77\%; FDA: 31 , 43 e 51\% e PB: 3,$1 ; 1,9$ e $1,1 \%$, respectivamente.
O consumo de suplementos foi afetado pela estratégia de suplementação $(\mathrm{P}<0,05)$. $\mathrm{O}$ menor consumo foi pelo grupo controle, o qual recebeu apenas SM (106g), o qual não diferiu ( $\mathrm{P}>0,05)$ quando acrescentado $25 \%$ de ureia (SP) $(196 \mathrm{~g})$. Todavia, as multimisturas foram mais consumidas $(\mathrm{P}<0,05)$, sendo que a ureia teve um efeito restritivo na ingestão voluntária, diminuindo de 852 $\mathrm{g} /$ dia quando foi servido a MM10 para 666 e $397 \mathrm{~g} /$ dia, respectivamente para MM15 e MM20(P<0,05) (Figura 2). De acordo com Baroni et al. (2010), o cloreto de sódio e a ureia são os principais limitadores de consumo.

Dentre os custos envolvidos no processo de suplementação, o transporte 
e a distribuição diária de suplementos para bovinos em pastejo são expressivos (DREWNOSKI \& POORE, 2012). Desta forma, a formulação de suplementos de auto regulação consumo aparece como estratégia de manejo para melhor racionalização da mão de obra e transporte (KUNKLE et al., 2000). Além disso, apresenta aspectos positivos sob o ponto de vista nutricional, tais como sincronização de energia-amônia, equilíbrio de $\mathrm{pH}$ e amônia (HERSOM, 2008).

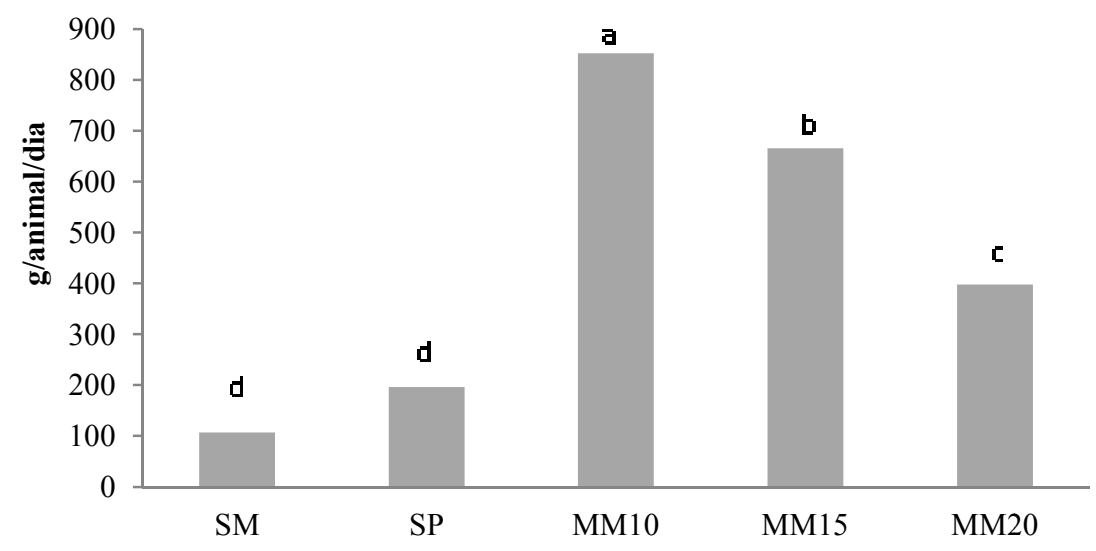

Figura 2. Consumo de suplementos de novilhos zebuínos em pastagens de capim-marandu diferidas $(\mathrm{SM}=\mathrm{sal}$ mineral; $\mathrm{SP}=$ sal proteinado com $25 \%$ de ureia; MM 10, MM15 e MM20 =multimisturas com 10, 15 e $20 \%$ de ureia, respectivamente)

As diferentes estratégias de suplementação não afetaram $(\mathrm{P}>0,05) \mathrm{o}$ tempo de pastejo, ócio, cocho e outras atividades (Figura 3). A suplementação de baixo consumo ocasionalmente influencia a utilização da forragem e parece exercer pequena influência nos componentes do comportamento de pastejo (BRANDYBERRY et al., 1991). Os suplementos aumentam a ingestão de forragem quando são usados com forragem de baixa qualidade cuja relação NDT:PB é maior que 7,0 (MOORE et al., 1999).

Por outro lado, Pardo et al. (2003) observaram efeito de substituição, em que o consumo de suplemento reduziu o tempo de pastejo e, consequentemente, a ingestão de forragem. Segundo esses autores, o decréscimo de pastejo nem sempre resulta no decréscimo no ganho de peso. A suplementação promove a elevação da ingestão de nutrientes digestíveis, que se correlaciona diretamente com desempenho (MATEUS et al., 2011; McGUIRE et al., 2013).

O tempo de pastejo variou de 11,6 a 13 h por dia (49 a $54 \%$ do tempo) (Figura $3)$, dentro da faixa de 6,8 a 13 h relatada por Kilgour (2012). O tempo de ruminação/ócio variou de 10,2 a 11,1h (42,5 a 46,3\% do tempo) (Figura 3). Bovinos em pastejo despendem de 4,7 a 10,2h em ruminação e 3,6 a 10,3 h em ócio (KILGOUR, 2012). No presente trabalho, os novilhos passaram em média $96,1 \%$ do tempo nas atividades de pastejo, ruminação e ócio, corroborando Kilgour et al. (2012). 


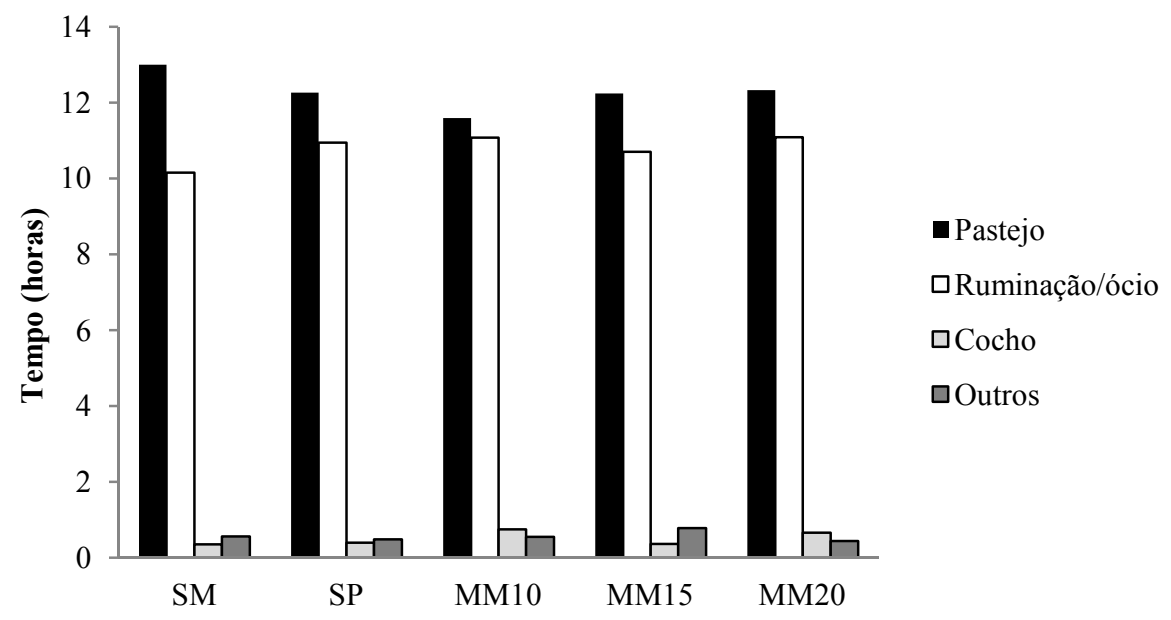

Figura 3. Tempo de pastejo, ruminação/ócio, cocho e outros de novilhos zebuínos recebendo diferentes suplementos alimentares na época seca $(\mathrm{SM}=\mathrm{sal}$ mineral; $\mathrm{SP}=\mathrm{sal}$ proteinado com 25\% de ureia; MM 10, MM15 e MM20 =multimisturas com 10, 15 e $20 \%$ de ureia, respectivamente)

Um aspecto importante para um melhor aproveitamento da forragem nas pastagens refere-se ao conhecimento dos horários de concentração do pastejo pelos animais, pois permite $\mathrm{o}$ estabelecimento de estratégias adequadas de manejo.

Claramente o ritmo circadiano influenciou o comportamento de pastejo (Figura 4). Independente da estratégia de suplementação adotada, em maior ou menor intensidade houve dois picos de pastejo entre 4:00 e 10:00 h.; e 14:00 e 19:00 h., sendo o último um pouco maior, considerando a intensidade (\%) e duração (tempo).

$O$ gado caracteristicamente segue um ritmo diurno, no qual a maioria da atividade de pastejo é realizada durante as horas de luz do dia (KILGOUR, 2012). Entretanto, a ocorrência de pastejo noturno esteve dentro do esperado, pois segundo Ebersohn et al. (1983), o bovino realiza pastejo à noite variando de 12 a $27 \%$ dessa atividade.

A ruminação/ócio concentrou-se durante a madrugada, mas ocorreu outro pico por volta das 11 horas ao meio dia, após o primeiro turno de pastejo (Figura 4). As idas ao cocho e bebedouro ocorreram geralmente durante o dia (Figura 4). Normalmente, os bovinos dividem o seu dia em períodos alternados de pastejo, ruminação/descanso (ócio). Existe um período de ruminação após cada período de pastejo, mas a maior parte da ruminação ocorre durante a noite (KILGOUR, 2012).

Por limitação de estrutura e de área experimental, o número de animais por tratamento foi relativamente pequeno, que provocou falta de uniformidade dos dados em algumas características avaliadas, como o ganho de peso. Nos próximos experimentos recomenda-se trabalhar com maior número de animais. O SM resultou em expressiva perda de peso (Figura 5), semelhante ao observado por Zanetti et al. (2000). De acordo com Reis et al. (2012), durante a estação seca o rebanho alimenta-se de forragem com baixo valor nutritivo, caracterizada pelo alto teor de fibra indigestível e teores de PB inferiores ao 
Rev. Bras. Saúde Prod. Anim., Salvador, v.17, n.3, p.461-473 jul./set., $2016 \quad \underline{\text { http://www.rbspa.ufba.br }}$ ISSN 15199940

nível crítico $(7 \%)$, limitando o seu consumo.

Assim, os nutrientes corporais são mobilizados para manutenção, acarretando em desempenho negativo. A utilização de ureia no sal proteinado
(SP) beneficiou o gado evitando a diminuição do peso corporal. Todavia, quando se busca ganho de peso, as multimisturas devem ser utilizadas, atingindo GPD de mais de $300 \mathrm{~g} / \mathrm{dia}$ quando a MM10 foi ofertada (Figura 5).

a)

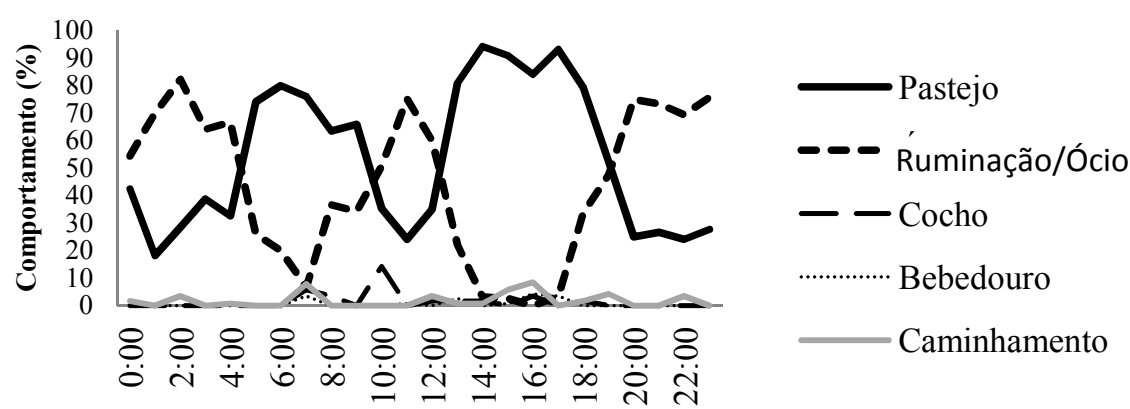

b)

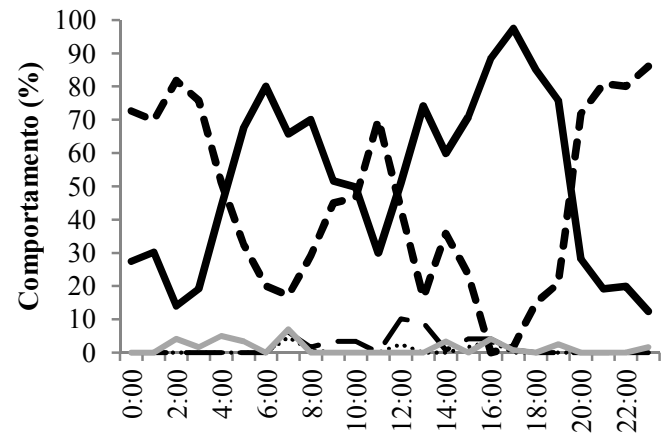

d)

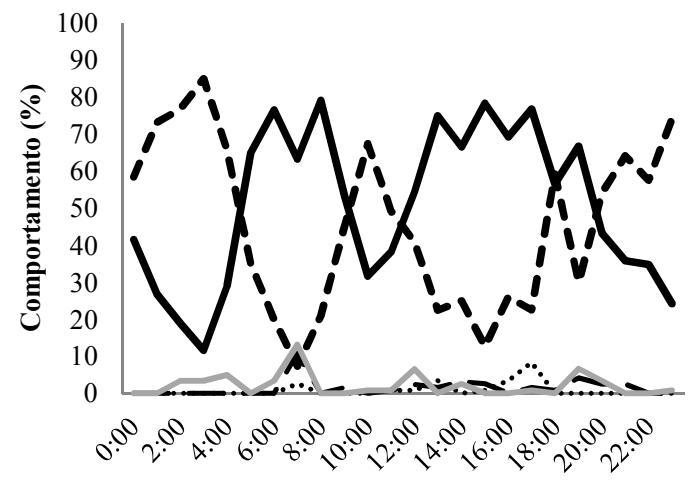

c)

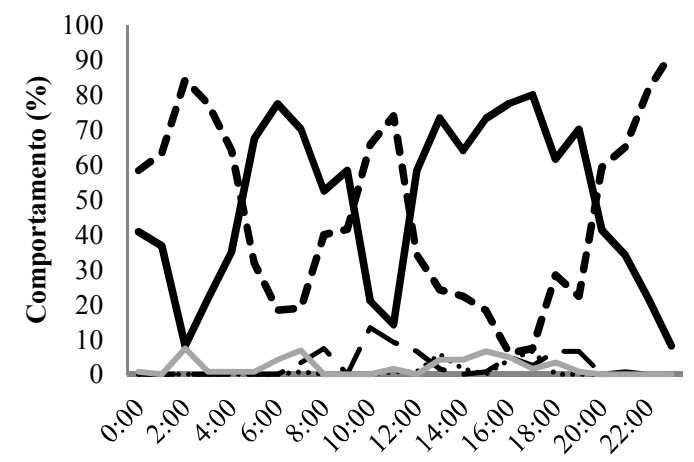

e)

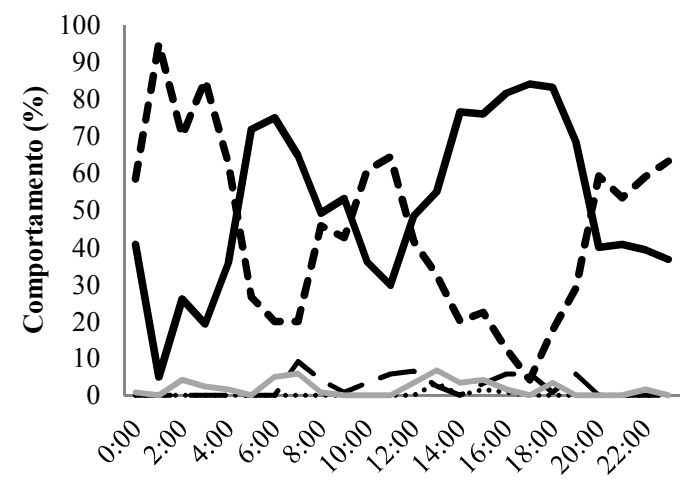

Figura 4. Comportamento de pastejo de novilhos zebuínos recebendo diferentes suplementos alimentares na época seca $(\mathrm{a}, \mathrm{SM}=$ sal mineral; $\mathrm{b}, \mathrm{SP}=\mathrm{sal}$ proteinado com 25\% de ureia; c, MM 10; d, MM15; e, MM20 = multimisturas com 10, 15 e $20 \%$ de ureia, respectivamente) 


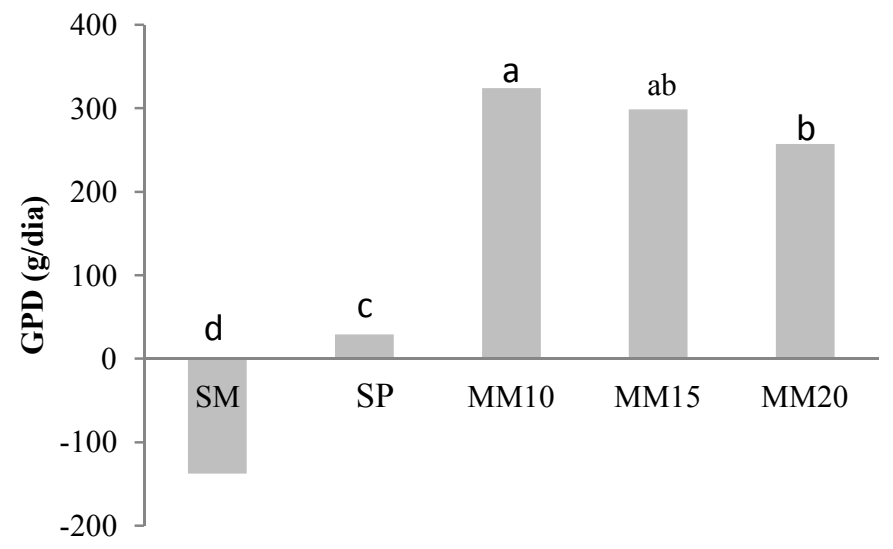

Figura 5. Ganho de peso diário (GPD) de novilhos zebuínos recebendo diferentes suplementos alimentares na época seca $(\mathrm{SM}=$ sal mineral; $\mathrm{SP}=$ sal proteinado com $25 \%$ de ureia; MM 10, MM15 e MM20 = multimisturas com 10, 15 e $20 \%$ de ureia, respectivamente)

De acordo com Hersom (2008), para ruminantes alimentados com forragens de baixa qualidade, a suplementação de proteína tem repetidamente melhorado o desempenho, pois corrige a deficiência de proteína $(\mathrm{N})$ na dieta e proporciona melhor sincronização do suprimento de energia e proteína no rúmen.

A adição de ureia no suplemento mineral, junto ao fornecimento de uma fonte de proteína verdadeira acrescida de energia, proporciona condições ótimas para $\mathrm{o}$ crescimento e multiplicação da flora do rúmen, que possibilita, desta forma, melhor degradabilidade dos alimentos com repercussão positiva no ganho de peso (CAMPOS NETO et al., 2004).

Diferentemente ao observado neste trabalho, Silva et al. (2008) não encontraram redução no desempenho dos animais em função do aumento dos níveis de ureia em substituição ao farelo de soja. Detmann et al. (2014), ao realizar metaanálise de dados de 44 experimentos envolvendo gado de corte em pastagens, encontraram evidências que o aumento da ingestão de PB via suplemento fornecido na época seca do ano resulta em diferencial positivo no GPD em relação a bovinos não-suplementados.

Segundo Baroni et al. (2010), testando níveis crescentes suplementação na terminação de bovinos Nelore em pastagens de capim-marandu na época seca do ano, houve efeito linear crescente sobre GPD, peso de carcaça, espessura de gordura subcutânea e rendimento de carcaça em função do consumo de suplemento. A suplementação, ao aumentar a média da taxa de ganho diário anual, traz outro benefício importante à pecuária, que é a redução do tempo de abate, que, por sua vez, entre outras vantagens, proporciona o maior retorno econômico e a obtenção de carcaças de melhor qualidade (FIGUEIREDO et al., 2007; REIS et al., 2012; BICALHO et al., 2014).

A melhor estratégia de suplementação depende de combinações favoráveis de preços relativos dos suplementos e pode ser definida pela diferença na taxa de retorno do capital investido em relação à ausência de suplementação (FIGUEIREDO et al., 2007). 
O custo diário da suplementação por animal variou com o consumo e o custo do suplemento. Excetuando-se o SM, as estratégias SP e MM20 apresentaram menores custos/animal/dia (R\$ 0,30; e $\mathrm{R} \$ 0,31$, respectivamente), mesmo essa última apresentando consumo bem mais elevado que a primeira, foi favorecida pelo menor custo por $\mathrm{kg}$ do suplemento
(Tabela 2). Somente a utilização de misturas múltiplas gerou resultado econômico positivo (Tabela 2). Para cada real empregado na suplementação com multimisturas, o resultado foi superior ao investimento em $\mathrm{R} \$ 0,47$; 0,79; e 1,49; para MM10, MM15 e MM20, respectivamente.

Tabela 2. Resultado bioeconômico de diferentes estratégias de suplementação para novilhos zebuínos mantidos em pastagem de capim-marandu diferida ( $\mathrm{SM}=$ sal mineral; $\mathrm{SP}=$ sal proteinado com 25\% de ureia; MM 10, MM15 e MM20 $=$ multimisturas com 10,15 e $20 \%$ de ureia, respectivamente)

\begin{tabular}{lccccc}
\hline $\begin{array}{l}\text { Estratégias de } \\
\text { suplementação }\end{array}$ & $\begin{array}{c}\text { Consumo de } \\
\text { suplemento } \\
\mathrm{PC})\end{array}$ & $\begin{array}{c}\text { Custo do } \\
\text { suplemento } \\
(\mathrm{R} \$ / \mathrm{kg})\end{array}$ & $\begin{array}{c}\text { Custo diário por } \\
\text { animal (R\$)* }\end{array}$ & $\begin{array}{c}\text { Benefício } \\
\text { diário (R\$)** }\end{array}$ & $\begin{array}{c}\text { Resultado } \\
\text { diário (R\$) }\end{array}$ \\
\hline SM & 0,04 & 1,63 & 0,17 & $-0,41$ & $-0,58$ \\
SP & 0,06 & 1,53 & 0,30 & 0,09 & $-0,21$ \\
MM10 & 0,25 & 0,77 & 0,66 & 0,97 & 0,31 \\
MM15 & 0,20 & 0,75 & 0,50 & 0,90 & 0,40 \\
MM20 & 0,11 & 0,79 & 0,31 & 0,77 & 0,46 \\
\hline
\end{tabular}

*Apenas considerando o preço dos ingredientes do suplemento; **Preço da $@=\mathrm{R} \$ 90,00 ; \mathrm{PC}=$ peso corporal.

Em virtude do elevado consumo da MM10, o custo/animal/dia foi mais alto, diminuindo sensivelmente o resultado econômico (Tabela 2). A melhor relação benefício:custo foi a utilização de $20 \%$ de ureia na multimistura (MM20, Tabela 2).

A fonte de proteína degradável no rúmen (PDR) mais barata existente no mercado é a ureia, que, quando utilizada associada às misturas minerais e grãos, possibilita redução na deficiência proteica de bovinos de corte durante o período de seca (REIS et al., 2012). Segundo Silva et al. (2008), avaliando a viabilidade econômica da ureia em substituição ao farelo de soja, todos os níveis de ureia testados (até 12\%) mostraram-se capazes de gerar receita positiva, enquanto os animais recebendo sal mineral geraram margem bruta negativa.

Com base neste trabalho, considerandose um lote de 100 cabeças suplementados por 150 dias, sairia de um resultado negativo de $\mathrm{R} \$ 8.729,00 \mathrm{e}$ $\mathrm{R} \$ 3.191,50$ nas estratégias SM e SP para $\mathrm{R} \$ 4.685, \mathrm{R} \$ 5.931,50$ e $\mathrm{R} \$$ $6.931,00$ positivos na MM10, MM15 e MM20, respectivamente. Esses resultados corroboram Campos Neto et al. (2004), ou seja, a suplementação mineral enriquecida com proteína $\mathrm{e}$ energia para bovinos sob regime de pastejo é fundamental para ganho de peso no período da seca, permitindo um retorno econômico compatível com o capital investido.

Em virtude do baixo teor de proteína presente no pasto (cerca de $2 \%$ ), a proteína para ganho foi oriunda do 
suplemento. Apesar do SP apresentar $70 \%$ de $\mathrm{PB}$, entre consumo de pasto, estimado em $1 \%$ do PC, e de suplementos, resultaria em proporções inferiores a 7\% de $\mathrm{PB}$, mínimo recomendado na literatura (McGUIRE et al, 2013; CANESIN et al., 2014), em virtude do baixo consumo do suplemento. Portanto, fontes de proteína verdadeira e energia devem estar presentes nos suplementos.

Usando o mesmo raciocínio, o MM10 proporcionou uma estimativa de percentual de PB na dieta na ordem de aproximadamente $10 \%$, aproveitando provavelmente um melhor $\mathrm{O}$ sincronismo com os carboidratos de fácil digestão pelas bactérias ruminais e produção de $\mathrm{AGV}$.

Dentre as estratégias de suplementação testadas para recria novilhos zebuínos mantidos em pastagens de capimmarandu na época seca do ano, o sal mineral puro resultou em expressiva perda de peso. Adicionando 25\% ureia ao suplemento praticamente manteve o peso dos novilhos. Entretanto, se ganhos são desejados, as multimisturas devem ser utilizadas com suplementos contendo de 10 a $20 \%$ de ureia.

A inclusão de $10 \%$ de ureia na multimistura promoveu maior GPD, que eventualmente poderia ser associado ao excesso proteico no caso do suplemento com 20\%, ocasionando o efeito negativo do "custo ureia". Todavia, o consumo de proteína em g/dia pelos animais recebendo suplementos com $20 \%$ de ureia foi menor que o tratamento com $10 \%$ de ureia.

Efetuando-se o cálculo da quantidade de nutrientes consumidos (NDT e PB) em virtude da suplementação (quantidade de suplemento $\mathrm{x}$ teor de nutrientes), observou-se que os animais recebendo suplemento com $10 \%$ de ureia consumiram 2,1 e 1,4 vezes mais NDT e $\mathrm{PB}$, respectivamente, em relação ao tratamento com $20 \%$ de ureia. Concluise assim que os melhores resultados de desempenho foram obtidos quando os animais consumiram mais nutrientes $(10 \%$ de ureia no suplemento). Entretanto, mesmo ganhando menos peso, proporcionalmente o menor consumo de suplemento promovido pela multimistura com $20 \%$ de ureia foi vantajoso quando observado a relação benefício-custo.

\section{REFERÊNCIAS}

ASSOCIATION OF OFFICIAL ANALYTICAL CHEMISTS - AOAC. Official methods of analysis. 17th ed., Gaithersburg, 2000.

BARONI, C.E.S.; LANA, R.P.; MANCIO, A.B.; QUEIROZ, A.C.; SVERZUT, C.B.; MENDONÇA, B.P.C. Desempenho de novilhos suplementados e terminados em pasto, na seca, e avaliação do pasto. Arquivo Brasileiro de Medicina Veterinária e Zootecnia, v.62, n.2, p.373-381, 2010.

BICALHO, F.L.; BARBOSA, F.A.; GRAÇA, D.S.; CABRAL FILHO, S.L.S.; LEÃO, J.M.; LOBO, C.F. Desempenho e análise econômica de novilhos Nelore submetidos a diferentes estratégias de suplementação alimentar nas fases de recria e engorda. Arquivo Brasileiro de Medicina Veterinária e Zootecnia, v.66, n.4, p.1112-1120, 2014.

BRANDYBERRY, S.D.; COCHRAN, R.C.; VAZANT, E.S.; DELCURTO, T.; CORAH, L.R. Influence of supplementation method on forage use and grazing behavior by beef cattle grazing bluestem range. Journal of Animal Science, v.69, n.10, p.41284136, 1991. 
Rev. Bras. Saúde Prod. Anim., Salvador, v.17, n.3, p.461-473 jul./set., $2016 \quad \underline{\text { http://www.rbspa.ufba.br }}$ ISSN 15199940

CABRAL, C.H.A.; PAULINO, M.F.; DETMANN, E.; VALADARES

FILHO, S.C.; BARROS, L.V.; VALENTE, E.E.L.; BAUER, M.O.; CABRAL, C.E.A. Levels of supplementation for grazing beef heifers. Asian-Australasian Journal of Animal Sciences, v.27, n.6, p.806-817, 2014.

CAMPOS NETO, O.; SCALZO, A.L.; FERNANDES, V.C.G. Avaliação técnica e econômica da suplementação mineral protéica-energética para bovinos da raça nelore, em pastejo de Brachiaria decumbens, no período da seca. Revista Científica Eletrônica de Medicina Veterinária, v.1, n.2, p.1-4, 2004.

CANESIN, R.C.; BERCHIELLI, T.T.; VEGA, A.; REIS, R.A.; MESSANA, J.D.; BALDI, F.; PÁSCOA, A.G. Reducing supplementation frequency for Nellore beef steers grazing tropical pastures. Scientia Agricola, v.71, n.2, p.105-113, 2014.

CAPPELLOZZA, B.I.; BOHNERT, D.W., SCHAUER, C.S., FALCK, S.J., VANZANT, E.S., HARMON, D.L., COOKE, R.F. Daily and alternate day supplementation of urea or soybean meal to ruminants consuming lowquality cool-season forage: II. Effects on ruminal fermentation. Livestock Science, v.155, n.2-3, p.214-222, 2013.

DETMANN, E.; VALENTE, E.E.L.; BATISTA, E.D.; HUHTANEN, P. An evaluation of the performance and efficiency of nitrogen utilization in cattle fed tropical grass pastures with supplementation. Livestock Science, v.162, n.1, p.141-153, 2014.
DREWNOSKI, M.E.; POORE, M.H. Effects of supplementation frequency on ruminal fermentation and digestion by steers fed medium-quality hay and supplemented with a soybean hull and corn gluten feed blend. Journal Animal Science, v.90, n.3, p.881-891, 2012.

EBERSOHN, J.P.; EVANS, J.; LIMPUS, J.F. Grazing time and its diurnal variation in beef steers in coastal South-East Queensland. Tropical Grasslands, v.17, n.2, p.76-81, 1983.

FIGUEIREDO, D.M.; OLIVEIRA, A.S.; SALES, M.F.L.; PAULINO, M.F.; VALE, S.M.L.R. Análise econômica de quatro estratégias de suplementação para recria e engorda de bovinos em sistema pasto-suplemento.

Revista Brasileira de Zootecnia, v.36, n.5, p.1443-1453, 2007.

HERSOM, M.J. Opportunities to enhance performance and efficiency through nutrient synchrony in foragefed ruminants. Journal Animal Science, v.86, p.306-317, 2008. Suppl.

KILGOUR, R.J. In pursuit of "normal": A review of the behaviour of cattle at pasture. Applied Animal Behaviour Science, v.138, n.1, p.1- 11, 2012.

KILGOUR, R.J.; UETAKE, K.; ISHIWATA, T.; MELVILLE, G.J. The behaviour of beef cattle at pasture.

Applied Animal Behaviour Science, v.138, n.1, p.12- 17, 2012.

KUNKLE, W.E.; JOHNS, J.T.; POORE, M.H.; HERD D.B. Designing supplementation programs for beef cattle fed forage-based diets. Journal Animal Science, v.77, n.1, p.1-11, 2000 . 
Rev. Bras. Saúde Prod. Anim., Salvador, v.17, n.3, p.461-473 jul./set., $2016 \quad \underline{\text { http://www.rbspa.ufba.br }}$ ISSN 15199940

MATEUS, R.G.; SILVA, F.F.; ÍTAVO, L.C.V.; PIRES, A.J.V.; SIVA, R.R.; SCHIO, A.R. Suplementos para recria de bovinos Nelore na época seca: desempenho, consumo e digestibilidade dos nutrientes. ActaScientiarum.

Animal Sciences, v.33, n.1, p.87-94, 2011.

McGUIRE, D.L.; BOHNERT, D.W.; SCHAUER, C.S.; FALCK, S.J.; COOKE, R.F. Daily and alternate day supplementation of urea or soybean meal to ruminants consuming lowquality cool-season forage: I - Effects on efficiency of nitrogen use and nutrient digestion. Livestock Science, v.155, n.2-3, p.205-213, 2013.

MEZZALIRA, J.C.; CARVALHO, P.C.F.; FONSECA, L.; BREMM, C.; REFFATI, M.V.; POLI, C.H.E.C.; TRINDADE, J.K. Aspectos metodológicos do comportamento ingestivo de bovinos em pastejo.

Revista Brasileira de Zootecnia, v.40, n.5, p.1114-1120, 2011.

MOORE, J.E.; BRANT, M.H.; KUNKLE, W.E.; HOPKINS, D.I. Effects of supplementation on voluntary forage intake, diet digestibility, and animal performance. Journal Animal Science, v.77, n.1, p.122-135, 1999. Suppl. 2,

PARDO, R.M.P.; FISCHER, V.; BALBINOTTI, M.; MORENO, C.B.; FERREIRA, E.X.; VINHAS, R.I.; MONKS, P.L. Comportamento ingestivo diurno de novilhos em pastejo submetidos a níveis crescentes de suplementação energética. Revista Brasileira de Zootecnia, v.32, n.6, p.1408-1418, 2003.
REIS, R.A.; RUGGIERI, A.C.; OLIVEIRA, A.A.; AZENHA, M.V.; CASAGRANDE, D.R. Suplementação como estratégia de produção de carne de qualidade em pastagenstropicais.

\section{Revista Brasileira de Saúde e} Produção Animal [online], v.13, n.3, p.642-655, 2012.

SILVA, D.J.; QUEIROZ, A.C. Análise de Alimentos: métodos químicos e biológicos. 3. ed. Viçosa, MG:

Universidade Federal de Viçosa, 2002. $235 p$.

SILVA, R.M.G.; CABRAS, L.S.; ABREU, J.G.; ZERVOUDAKIS, J.T.; SOUZA, A.L.; OCHOVE, V.C.C.; MIRANDA, L.; OLIVEIRA, I.S. Níveis de ureia em suplementos múltiplos para bovinos de corte durante a época seca.

\section{Revista Brasileira de Saúde e}

Produção Animal [online], v.9, n.3, p. 543-553, 2008.

SILVA, R.R.; PRADO, I.N.; SILVA, F.F.; ALMEIDA, V.V.S.; SANTANA JÚNIOR, H.A.; QUEIROZ, A.C.; CARVALHO, G.G.P.; BARROSO, D.S. Comportamento ingestivo diurno de novilhos Nelore recebendo níveis crescentes de suplementação em pastejo de capim-braquiária. Revista Brasileira de Zootecnia, v.39, n.9, p.2073-2080, 2010 .

ZANETTI, M.A.; RESENDE, J.M.L.; SCHALCH, F.; MIOTTO, C.M. Desempenho de novilhos consumindo suplemento mineral proteinado convencional ou com ureia. Revista Brasileira Zootecnia, v.29, n.3, p.935939, 2000.

Data de recebimento: 22/09/2015

Data de aprovação: 06/06/2016 